\title{
Dissociation in schizophrenia and borderline personality disorder
}

\author{
This article was published in the following Dove Press journal: \\ Neuropsychiatric Disease and Treatment \\ 17 March 2014 \\ Number of times this article has been viewed
}

\section{Ondrej Pec ${ }^{1,2}$ \\ Petr Bob ${ }^{1,3}$ \\ Jiri Raboch'}

'Center for Neuropsychiatric Research of Traumatic Stress, Department of Psychiatry, First Faculty of Medicine, Charles University, Prague, ${ }^{2}$ Psychotherapeutic and Psychosomatic Clinic ESET, Prague, ${ }^{3}$ Central European Institute of Technology, Faculty of Medicine, Masaryk University, Brno, Czech Republic
Correspondence: Petr Bob Department of Psychiatry, Charles University, First Faculty of Medicine, Ke Karlovu II, I2800 Prague, Czech Republic Email petrbob@netscape.net
Background: Dissociation likely plays a key role in schizophrenia and borderline personality disorder (BPD), although empirical studies that compare specific manifestations of these symptoms in schizophrenia and BPD are rare. In this context, the purpose of this study was to compare the occurrence of dissociative and other psychopathological symptoms in these disorders, and to assess the possible influence of antipsychotic medication on the dissociative symptoms.

Methods: We assessed 31 patients with schizophrenia and 36 patients with BPD. Dissociative symptoms were measured by the Dissociative Experiences Scale (DES), symptoms related to stress and traumatic experiences were assessed using the Trauma Symptom Checklist-40 (TSC-40), and other psychopathological symptoms were measured with the Health of the Nation Outcome Scales (HoNOS). We also assessed actual daily doses of antipsychotic medication in chlorpromazine equivalents in all participants.

Results: The results show that symptoms of traumatic stress measured by the TSC-40 had significantly higher scores in the BPD group. The data also show that dissociative symptoms (DES) were significantly correlated with symptoms of traumatic stress (TSC-40) and with symptoms assessed by the HoNOS. Remarkably significant correlations were found between levels of antipsychotic medication and the DES and between antipsychotic medication and the depersonalization/derealization component of the DES in BPD patients.

Conclusion: The results support an important role of dissociative processes in schizophrenia and BPD and suggest a significant relationship between manifestations of dissociative symptoms in BPD and antipsychotic medication.

Keywords: dissociation, stress-related symptoms, schizophrenia, borderline personality disorder, antipsychotic medication

\section{Introduction}

Dissociation in principle describes fragmentation of conscious experience that is typically related to long-term or acute stress that significantly disturbs self-concept, identity, memory, and perception of the external world. ${ }^{1-4}$ Consequently, these alterations may be linked to marked and abrupt changes in patterns of neural activity that may dissociate, or split off, certain external and internal stimuli and information out of awareness, which may lead to distinct states of divided consciousness. . $^{3,5-8}$

Dissociation also reflects shifts of mind related to a consciously experienced conflict of opposing mental forces. In the similar context as Janet, also Bleuler coined the term splitting and described the process of mental fragmentation in schizophrenia as a basic step in the pathogenesis of the disease. ${ }^{4,5,9}$ The term fragmentation of consciousness in the sense of splitting was also defined in borderline personality disorder (BPD) as a 
specific form of dissociation, and recent studies suggest that the relationship between dissociative symptoms and BPD per se is very close. ${ }^{10-12}$

With the aim of finding specific relationships between dissociative symptoms and other symptoms in BPD and schizophrenia, we assessed both groups of patients with the aim of comparing the occurrence of dissociation and also of assessing the possible influence of antipsychotic medication using chlorpromazine equivalents (EC).

\section{Materials and methods Participants}

The participants were recruited from regular daily treatment programs for outpatients with schizophrenia or BPD at the Psychotherapeutic and Psychosomatic Clinic ESET in Prague. The participants had a diagnosis of schizophrenia or BPD. Exclusion criteria were organic illnesses involving the central nervous system, substance and/or alcohol abuse, and mental retardation (Raven's IQ <90). ${ }^{13}$ Clinical diagnoses were based on DSM-IV (Diagnostic and Statistical Manual of Mental Disorders, Fourth Edition) criteria and were reassessed using The Mini-International Neuropsychiatric Interview ${ }^{14}$ in patients with schizophrenia and confirmed by semistructured interview in patients with BPD. We calculated actual daily doses of antipsychotic medication in EC for all participants. ${ }^{15}$

The schizophrenia sample comprised 31 patients ( 15 men and 16 women) of mean age $36.2 \pm 9.5$ years. Their mean duration of psychiatric treatment was $13.3 \pm 8.2$ years, and they had an average of 4.4 hospitalizations. The BPD sample comprised 36 patients (eleven men and 25 women) of mean age $31.0 \pm 8.7$ years. Their mean duration of psychiatric treatment was $6.6 \pm 4.1$ years, and they had an average of 2.39 hospitalizations. Because of their different durations of psychiatric treatment, the patients also had a different medication history and as measurable equivalent characterizing their current medication we have used EC.

\section{Psychometric measures}

We used the Dissociative Experiences Scale (DES) to screen for dissociative symptoms. ${ }^{16}$ The DES is a 28 -item self-report questionnaire that evaluates the frequencies of various experiences of dissociative phenomena in the patient's everyday life. Each item ranges from 0 to 100 and the mean of all item scores is calculated as the DES score. For more detailed assessment of the DES items, we analyzed the DES factors that have been used in previous research studies. ${ }^{17}$ In this analysis, we used three factors focused on absorption (items 2, 14, 15, 17, 18, and 20), amnesia related to dissociative states (items 3, 4, 5, 8, 25, and 26), and depersonalization/derealization (items 7, 11, 12, 13, 27, and 28). In the present study, we used the Czech version of the DES; like the original English version, it shows high reliability and internal consistency (Cronbach's alpha 0.92, test-retest reliability after one week 0.91$){ }^{18,19}$

Symptoms related to stress and traumatic experiences were measured using the Trauma Symptom Checklist-40 (TSC-40). ${ }^{20}$ This scale was designed for measurement of posttraumatic symptomatology associated with childhood trauma. The TSC-40 is a self-reported scale containing 40 items with six subscales, ie, dissociation, anxiety, depression, a sexual abuse trauma index, sexual problems, and sleep disturbances. The Czech version of the TSC-40 has high reliability and internal consistency (Cronbach's alpha 0.91, test-retest reliability after one week 0.88$){ }^{21}$

Psychotic manifestations were measured using the Health of the Nation Outcome Scales (HoNOS) in both groups of patients. ${ }^{22}$ The scale includes twelve items (overactive, aggressive, disruptive or agitated behavior; nonaccidental self-injury; problem drinking or drug-taking; cognitive problems; physical illness or disability problems; problems with hallucinations or delusions; problems with depressed mood; other mental and behavioral problems; problems with relationships; problems with activities of daily living; problems with living conditions; problems with occupation and activities). There are two versions available, ie, the version for external evaluators and the self-rating version for patients. Both versions were translated into the Czech language (Cronbach's alpha 0.797 , test-retest reliability after one week 0.85$)^{23}$

\section{Statistical analysis}

Statistical evaluation of the results for the DES and other psychometric measures included descriptive statistics, the Mann-Whitney $U$ test for independent samples, and Spearman correlation coefficients. Nonparametric analyses were preferred because the DES data were not normally distributed. All the methods used for statistical evaluation were performed using Statistica version 6 software (StatSoft Inc., Tulsa, OK, USA). To prevent type II error, which would not be able to reject the null hypothesis that symptoms of dissociation are not linked to stress-related psychopathological symptoms, we performed a power analysis and assessed the effect sizes by characterizing differences between means or correlation coefficients of the samples. 


\section{Results}

We compared scores from the psychometric measures using the Mann-Whitney $U$ test to test for differences in dissociation, other psychopathological manifestations, and use of antipsychotic medication between the two disorders (see Table 1). Although the differences in DES scores between patients with BPD and those with schizophrenia were not statistically significant, scores for symptoms of traumatic stress measured by the TSC- 40 were significantly higher in the BPD group.

External evaluations as well as self-rating on the HoNOS showed that the BPD group had significantly higher scores than patients with schizophrenia. Nevertheless, in several subscales of the HoNOS, external evaluators reported that the schizophrenia group had higher scores for cognitive problems (1.55 in schizophrenia versus 0.66 in $\mathrm{BPD}, P=0.0001$ ) and positive symptoms (1.26 in schizophrenia versus 0.54 in BPD, $P=0.0273$ ). Doses of antipsychotics measured by $\mathrm{EC}$ were significantly higher in the schizophrenia group. In the power analysis, we tested the differences between means, and found that all these had a strong effect size ( $r \geq 0.5$; Table 1$)$.

We calculated Spearman correlation coefficients in both patient samples to assess the relationship between dissociation and other psychometric measures and the possible influence of antipsychotic medication on this relationship. The results show that scores on the DES, TSC-40, and HoNOS were significantly correlated (see Table 2). Interesting, statistically significant correlations were found in BPD patients between levels of EC and the DES score (Spearman's correlation $R=0.37$; refined Fisher's exact test $Z=0.14$ ) and between EC and depersonalization/derealization score on the DES (Spearman's correlation $R=0.37$; refined Fisher's exact test $Z=0.38$ ).

\section{Discussion}

Our results show that dissociative symptoms and symptoms of traumatic stress are significantly correlated in patients with

Table I Comparison between schizophrenia and bipolar disorder using the Mann-Whitney $U$ test

\begin{tabular}{llllll}
\hline & $\begin{array}{l}\text { Schizophrenia } \\
\mathbf{n = 3}\end{array}$ & $\begin{array}{l}\text { BPD } \\
\mathbf{n = 3 6}\end{array}$ & $\mathbf{M W}$ & $\boldsymbol{P}$-value & $\boldsymbol{r}$ \\
\hline DES & 13.7 & 18.54 & -1.8 & 0.0730 & 0.36 \\
TSC-40 & 34.1 & 54.19 & -3.7 & 0.0002 & 0.95 \\
HoNOS (E) & 11.6 & 15 & -2.6 & 0.0085 & 0.81 \\
HoNOS (S) & 7.8 & 14.25 & -3.9 & 0.0000 & 0.97 \\
EC & 518.4 & 98.6 & 5.5 & 0 & 0.97 \\
\hline
\end{tabular}

Abbreviations: BPD, bipolar disorder; DES, Dissociative Experiences Scale; TSC-40, Trauma Symptom Checklist-40; HoNOS (E), version for external evaluation of HoNOS (mean); HoNOS (S), self-rating version of HoNOS (mean); EC, day dosages of antipsychotic medication in equivalents of chlorpromazine (mean in $\mathrm{mg}$ ); $r$, standardized effect size; MW, Mann-Whitney $U$ test.

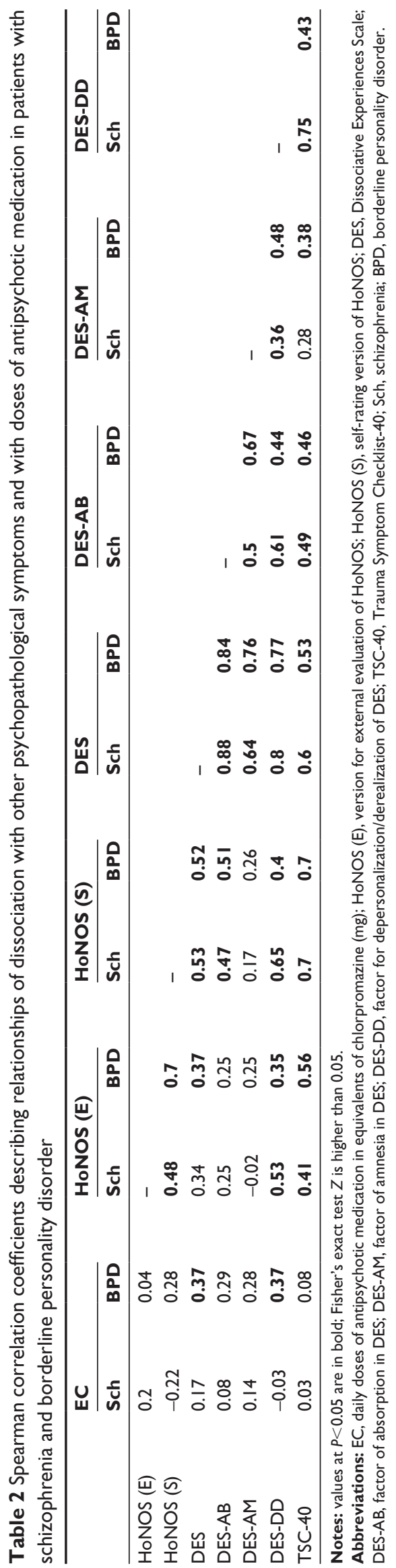

Neuropsychiatric Disease and Treatment 2014:10

submit your manuscript | www.dovepress.com 
BPD and in those with schizophrenia. The data also show that symptoms of traumatic stress are higher in BPD than in schizophrenia, which is in agreement with the findings of other studies. ${ }^{24-26}$

On the other hand, DES and TSC-40 scores were significantly correlated with symptoms of psychosis in both disorders and, as in other studies of patients with schizophrenia, symptoms of traumatic stress were associated with psychotic symptoms, ${ }^{27,28}$ higher levels of anxiety, and other psychopathological symptoms. ${ }^{29-33}$ In agreement with other studies, we also found that dissociation in schizophrenia is closely related to symptoms of trauma. ${ }^{34-41}$ Similar relationships between stress and dissociation have also been found in patients with BPD. ${ }^{10,42}$

An interesting finding of this study was the correlation between doses of antipsychotics measured in EC and dissociative symptoms in patients with BPD. This result suggests a specific psychotropic effect of antipsychotic medication in these patients. To the best of our knowledge, this has not been reported in the scientific literature before. Because our patients had different medication histories, it is necessary to investigate the possible relationship between medication and dissociative symptoms further in follow-up studies that could explain certain details and specific influences of medication on neurotransmitter systems. Nevertheless, the statistical finding of this relationship in the BPD group but not in schizophrenia group is of interest although further research is necessary. The possible influence of medication on dissociative symptoms might reflect the extremely important role of stress in BPD. According to current data, stress represents a more significant factor in BPD etiology than in schizophrenia. ${ }^{43,44}$ Recent data show that antipsychotic treatment likely decreases activation of the anterior cingulate cortex..$^{45,46}$ In this context it is possible that conscious conflicting ${ }^{47,49}$ experiences due to antipsychotic medication in BPD may decrease conscious awareness of conflicting stressful experiences and cause their dissociation that may produce the dissociative symptoms measured by the DES. Although this interpretation is currently speculative, it might be useful for further research that could have significant consequences for the treatment of patients with BPD.

\section{Conclusion and perspectives}

These results support the conceptual but empirically rare findings concerning the important role of dissociative processes in schizophrenia and BPD and the specific relationship between them. A novel contribution of this study that needs further research is the significant finding that manifestations of dissociative symptoms might be specifically linked to antipsychotic medication in patients with BPD but not in those with schizophrenia.

\section{Acknowledgment}

The study was supported by a grant from Charles University (PRVOUK), project grants provided by the Czech Ministry of Education (LH11032) and the "CEITEC - Central European Institute of Technology" (CZ.1.05/1.1.00/02.0068) from the European Regional Development Fund.

\section{Disclosure}

The authors report that they have no conflicts of interest in this work.

\section{References}

1. Breuer J, Freud S. Studies in Hysteria. New York, NY, USA: Basic Books; 1895.

2. Stone MH. Toward a psychobiological theory of borderline personality disorder: Is irritability the red thread that runs through borderline conditions? Dissociation. 1988;1:2-15.

3. Bob P. Pain, dissociation and subliminal self-representations. Conscious Cogn. 2008;17:355-369.

4. Bob P. Dissociation, epileptiform discharges and chaos in the brain: toward a neuroscientific theory of dissociation. Act Nerv Super (Praha). 2012;54:84-107.

5. Hilgard ER. Divided Consciousness. Multiple Control in Human Thought and Action. New York, NY, USA: Wiley; 1986.

6. Crawford HJ. Brain dynamics and hypnosis. Int J Clin Exp Hypn. 1994;42:204-232.

7. Rainville P, Hofbauer RK, Bushnell MC, Duncan GH, Price DD. Hypnosis modulates activity in brain structures involved in the regulation of consciousness. J Cogn Neurosci. 2002;14:887-901.

8. Vermetten E, Douglas BJ. Functional brain imaging and the induction of traumatic recall: a cross-correlational review between neuroimaging and hypnosis. Int J Clin Exp Hypn. 2004;52:280-312.

9. Bleuler E. Dementia Praecox or the Group of Schizophrenias. Zinkin J, translator. New York, NY, USA: International Universities Press; 1950.

10. Korzekwa MI, Dell PF, Links PS, Thabane L, Fougere P. Dissociation in borderline personality disorder: a detailed look. JTrauma Dissociation. 2009;10:346-367.

11. Zanarini MC, Jager-Hyman S. Dissociation in borderline personality disorder. In: Dell PF, O'Neil JA, editors. Dissociation and the Dissociative Disorders. DSM-V and Beyond. New York, NY, USA: Routledge; 2009.

12. Zanarini MC, Frankenburg FR, Jager-Hyman S, et al. The course of dissociation for patients with borderline personality disorder and Axis II comparison subjects: a 10-year follow up. Acta Psychiatr Scand. 2008;118:291-296.

13. Raven JC. Guide to the Standard Progressive Matrices. London, UK: HK Lewis; 1960.

14. Sheehan DV, Lecrubier Y, Sheehan KH, et al. The Mini-International Neuropsychiatric Interview (MINI): the development and validation of a structured diagnostic psychiatric interview for DSM-IV and ICD-10. J Clin Psychiatry. 1998;59 Suppl 20:22-33.

15. Woods SW. Chlorpromazine equivalent doses for the newer atypical antipsychotics. J Clin Psychiatry. 2003;64:663-667.

16. Bernstein EM, Putnam FW. Development, reliability, and validity of a dissociation scale. J Nerv Ment Dis. 1986;174:727-735. 
17. Waller NG, Putnam FW, Carlson EB. Types of dissociation and dissociative types: a taxometric analysis of dissociative experiences. Psychol Methods. 1996;1:300-321.

18. Bob P. [Dissociation processes and their measurement]. Ceska Slov Psychiatr. 2000;96:301-309. Czech.

19. Ptacek R, Bob P, Paclt I. [Dissociative experiences scale - Czech version]. Cesk Psychol. 2006;50:262-272.

20. Elliott DM, Briere J. Sexual abuse trauma among professional women: validating the Trauma Symptom Checklist-40 (TSC-40). Child Abuse Negl. 1992;16:391-398.

21. Bob P, Ptacek R, Paclt I, et al. [Dissociation and symptoms of complex partial epilepsy in depressed patients]. Ceska Slov Psychiatr. 2003;99:82-88. Czech.

22. Wing JK, Curtis RH, Beevor AS. HoNOS: Health of the Nation Outcome Scales: Report on Research and Development Jul 1993-Dec 1995. London, UK: Royal College of Psychiatrists; 1996.

23. Pec O, Cechova D, Pecova J, et al. [HoNOS (Health of the Nations Outcome Scales) - an adaptation of the tool for the assessment of symptoms and social functions in serious mentally ill in the Czech conditions and its use]. Ceska Slov Psychiatr. 2009;105:245-249. Czech.

24. Kingdon DG, Ashcroft K, Bhandari B, et al. Schizophrenia and borderline personality disorder similarities and differences in the experience of auditory hallucinations, paranoia, and childhood trauma. J Nerv Ment Dis. 2010;198:399-403.

25. Putnam FW, Carlson EB, Ross CA, et al. Patterns of dissociation in clinical and nonclinical samples. J Nerv Ment Dis. 1996;11:673-679.

26. Brunner R, Parzer P, Schmitt R, Rescha F. Dissociative symptoms in schizophrenia: a comparative analysis of patients with borderline personality disorder and healthy controls. Psychopathology. 2004;37: 281-284.

27. Read J, van Os J, Morrison AP, Ross CA. Childhood trauma, psychosis and schizophrenia: a literature review with theoretical and clinical implications. Acta Psychiatr Scand. 2005;112:330-350.

28. Ross C, Anderson G, Clark P. Childhood abuse and positive symptoms of schizophrenia. Hosp Community Psychiatry. 1994;45:489-491.

29. Lysaker PH, Salyers MP. Anxiety symptoms in schizophrenia spectrum disorders: associations with social function, positive and negative symptoms, hope and trauma history. Acta Psychiatr Scand. 2007;116:290-298.

30. Lysaker PH, Meyer PS, Evans JD, Clements CA, Marks KA. Childhood sexual trauma and psychosocial functioning in adults with schizophrenia. Psychiatr Serv. 2001;52:1485-1488.

31. Lysaker PH, Nees MA, Lancaster RS, Davis LW. Vocational function among persons with schizophrenia with and without history of childhood sexual trauma. J Trauma Stress. 2004;17:435-438.

32. Janssen I, Krabbendam L, Bak M, et al. Childhood abuse as a risk factor for psychotic experiences. Acta Psychiatr Scand. 2004;109:38-45.

33. Renard SB, Pijnenborg M, Lysaker PH. Dissociation and social cognition in schizophrenia spectrum disorder. Schizophr Res. 2012;137: 219-223.
34. Sar V, Taycan O, Bolat N, et al. Childhood trauma and dissociation in schizophrenia. Psychopathology. 2010;43:33-40.

35. Schafer I, Fisher HL, Aderhold V, et al. Dissociative symptoms in patients with schizophrenia: relationships with childhood trauma and psychotic symptoms. Compr Psychiatry. 2012;53:364-371.

36. Moskowitz A, Read J, Farrelly S, Rudegeair T, Williams O. Are psychotic symptoms traumatic in origin and dissociative in kind? In: Dell PF, O'Neil JA, editors. Dissociation and the Dissociative Disorders. DSM-V and Beyond. New York, NY, USA: Routledge; 2009.

37. Ross CA. The theory of dissociative subtype of schizophrenia. In: Dell PF, O'Neil JA, editors. Dissociation and the Dissociative Disorders. DSM-V and Beyond. New York, NY, USA: Routledge; 2009.

38. Spitzer C, Haug HJ, Freyberger HJ. Dissociative symptoms in schizophrenic patients with positive and negative symptoms. Psychopathology. 1997;30:67-75.

39. Vogel M, Spitzer C, Barnow S, Freyberger HJ. The role of trauma and PTSD-related symptoms for dissociation and psychopathological distress in inpatients with schizophrenia. Psychopathology. 2006;39: 236-242.

40. Vogel M, Kuwert P, Spitzer C, Möller B, Freyberger HJ, Grabe HJ. Association of childhood neglect with adult dissociation in inpatients with schizophrenia. Psychopathology. 2009;42:124-130.

41. Vogel M, Schatz D, Spitzer C, et al. A more proximal impact of dissociation than of trauma and posttraumatic stress disorder on Schneiderian symptoms in patients diagnosed with schizophrenia. Compr Psychiatry. 2009;50:128-134.

42. Howel EF, Blizard RA. Chronic relational trauma disorder: a new diagnostic scheme for borderline personality and the spectrum of dissociative disorders. In: Dell PF, O’Neil JA, editors. Dissociation and the Dissociative Disorders. DSM-V and Beyond. New York, NY, USA: Routledge; 2009.

43. Weber K, Miller GA, Schupp HT, et al. Early life stress and psychiatric disorder modulate cortical responses to affective stimuli. Psychophysiology. 2009;46:1234-1243.

44. Barnow S, Arens EA, Sieswerda S, Dinu-Biringer R, Spitzer C, Lang S. Borderline personality disorder and psychosis: a review. Curr Psychiatry Rep. 2010;12:186-195.

45. Yan H, Tian L, Yan J, et al. Functional and anatomical connectivity abnormalities in cognitive division of anterior cingulate cortex in schizophrenia. PLoS One. 2012;7:e45659.

46. Yücel M, Brewer WJ, Harrison BJ, et al. Anterior cingulate activation in antipsychotic-naïve first-episode schizophrenia. Acta Psychiatr Scand. 2007;115:155-158.

47. Botvinick MM, Cohen JD, Carter CS. Conflict monitoring and anterior cingulate cortex: an update. Trends Cogn Sci. 2004;8:539-546.

48. Kerns JG, Cohen JD, MacDonald AW 3rd, Cho RY, Stenger VA, Carter CS. Anterior cingulate conflict monitoring and adjustments in control. Science. 2004;303:1023-1026.

49. Kerns JG, Cohen JD, MacDonald AW 3rd, et al. Decreased conflict- and error-related activity in the anterior cingulate cortex in subjects with schizophrenia. Am J Psychiatry. 2005;162:1833-1839.
Neuropsychiatric Disease and Treatment

\section{Publish your work in this journal}

Neuropsychiatric Disease and Treatment is an international, peerreviewed journal of clinical therapeutics and pharmacology focusing on concise rapid reporting of clinical or pre-clinical studies on a range of neuropsychiatric and neurological disorders. This journa is indexed on PubMed Central, the 'PsycINFO' database and CAS.

\section{Dovepress}

The manuscript management system is completely online and includes a very quick and fair peer-review system, which is all easy to use. Visit http://www.dovepress.com/testimonials.php to read real quotes from published authors. 